\title{
Health Assets and Frailty: Positive Psychosocial Resources and Health Status in Older Adult, a Prospective Cohort Study
}

Kate Gregorevic ( $\square$ kate.gregorevic@gmail.com )

Northern Hospital https://orcid.org/0000-0002-2248-761X

Ruth E Hubbard

The University of Queensland

Nancye M Peel

University of Queensland

Wei Tong Lau

Logan Hospital

Jethro Wu

Dell Seton Medical Center

Bradley Crammond

Monash University

Wen Kwang Lim

Royal Melbourne Hospital

Research article

Keywords: Frailty , Health Assets, Hospital Mortality

Posted Date: January 16th, 2020

DOI: https://doi.org/10.21203/rs.2.15969/v3

License: (c) (1) This work is licensed under a Creative Commons Attribution 4.0 International License. Read Full License 


\section{Abstract}

Background: Although frailty is predictive of poorer outcomes for hospitalised older adults, it does not account for all variation in outcomes. Health assets are protective factors associated with wellbeing that may moderate frailty associated mortality and functional decline Objective: To determine whether frail older adults with a higher number of health assets have improved outcomes Design: Prospective cohort study Methods: Adults aged 70 and older with an unplanned admission to hospital were included. Recruitment took place on general medical, orthogeriatric and subacute wards of two hospitals in Australia. The Health Assets Index (HAl), frailty, functional status and covariates were measured at the time of recruitment. Outcomes were mortality at 30 days and functional decline at the time of discharge. Results: There were 298 participants, with an average age of 84.7 and $66 \%$ were women. $80.1 \%$ were frail. The mean score on the HAI was 10.86 with a range of 5.5-15. 56.4\% of participants had functional decline on discharge from hospital with 30 day mortality of $5.7 \%$. There was an inverse relationship between frailty and health assets. Neither frailty or a higher number of health assets alone predicted outcomes. In a post-hoc analysis to account for interaction, a higher number of health assets was protective against mortality for the least frail. This relationship was reversed at higher levels of frailty. Conclusions: A higher number of Health Assets correlated with a lower level of frailty. Although Health Assets alone did not predict mortality, this relationship may be moderated by frailty.

\section{Background}

Unplanned admission to hospital for older adults frequently results in adverse outcomes: around $7.5 \%$ will be deceased within 30 days $^{1}$ and $30-40 \%$ leave with functional decline which confers a poor long-term prognosis. $^{2,3}$

Although increasing frailty is predictive of adverse outcomes, measuring frailty alone does not fully explain trajectories of survival and recovery. ${ }^{4}$ Health assets are determining factors that predict health and recovery over and above conventional risk factors and are also desirable in their own right. ${ }^{5}$ The concept of health assets has primarily been developed in the community. Health assets have been identified across multiple domains including biological (eg. low cholesterol), functional (eg. ability to undertake community activities) and subjective (eg. a sense of wellbeing). ${ }^{6}$ In community studies, health assets can act individually and cumulatively to improve survival and health status. ${ }^{5,7}$ Although the protective effect of health assets in the community has been established, their impact in the hospital setting is less well characterised. 8,9 Systematic reviews have demonstrated that individual health assets can improve outcomes, ${ }^{7,9}$ but many health assets have been examined only in isolation and not in a model with frailty. ${ }^{9}$

A Health Assets Index ( $\mathrm{HAl}$ ) was developed to measure health assets in the acute health care setting. The aims of this study were:

1. To Examine the relationship between frailty and Health Assets 
2. To determine the validity of the HAl for the prediction of mortality and functional decline.

\section{Methods}

\section{Setting and Sample}

The study protocol has been previously published. ${ }^{10}$ In brief, study recruitment took place in general medical, orthogeriatric and subacute wards of two hospitals in Victoria and Queensland, Australia. Eligible participants were adults aged 70 and older who had an unplanned admission to hospital. Participants could be recruited at any time during hospital admission. Participants were excluded if they had cognitive impairment with no available next of kin, non-English speaking, severe psychiatric disturbance, too medically unwell or receiving terminal care.

Researchers screened for cognitive impairment by discussion with medical and nursing staff. Researchers also used clinical judgment when seeking consent, in case of new onset of delirium. If researchers or medical staff identified cognitive impairment, the next of kin was asked for formal consent. Participants deemed not able to consent were still asked about their willingness to participate to ensure they did not object to being involved.

\section{$\underline{\text { Measures }}$}

The Health Assets Index (HAl) (supplementary table 1) was developed based on variables identified by systematic review and a secondary analysis of a large, Australian inpatient dataset. ${ }^{4,9}$ The following criteria were chosen for variables to be included in the HAl:

- Associated with positive health outcomes.

- Not included in the frailty index.

- Not present or absent in greater than $95 \%$ of patients.

- As a group, the candidate assets must cover a range of domains

- Assets must be age appropriate

The proposed scoring system was that each asset would be scored between 0-1 with a higher score corresponding to a higher number of health assets.

\section{HAl and covariates}

Measures were obtained using patient reported data, observation and medical records. At the time of recruitment, health assets were recorded on the HAl by trained assessors. Covariates measured included frailty, illness severity, sex and usual place of residence. Frailty was measured based on premorbid function at two weeks before admission using an FI (see supplementary data S1), which has been previously validated in the inpatient setting. Although the timing of recruitment from admission was variable, the FI has previously been used at different times during the admission, and remains valid. 
Illness severity was measured with the Modified Early Warning System (MEWS), which uses routine observations at the time of admission. ${ }^{11}$

Katz Activities of daily living (ADLs) ${ }^{12}$ and Instrumental Activities of Daily Living (iADLs) at the participant's reported baseline were recorded with the same scoring used for men and women.

\section{Primary Outcomes}

The primary outcomes were:

1. Mortality at 30 days after discharge, which was identified on hospital records.

2. Functional decline at the time of discharge from hospital which was defined as a decreased score on ADLs compared to baseline or new discharge to residential aged care

\section{Secondary Outcomes}

1. Total length of stay including acute and subacute wards

2. Readmission within 30 days, identified on hospital record or phone call

3. Functional decline at 30 days post discharge home, which was defined as a decreased composite score for ADLs and IADLs at 30 days post discharge. Participants who were readmitted to hospital were excluded from this analysis as the interceding illness or injury that precipitated readmission would provide a confounder for functional decline.

Participants admitted from residential care were excluded from analyses of functional decline at 30 days post discharge as IADLs are not applicable to this population. Those discharged to a new residential aged care were assumed to have persistent functional decline.

\section{Analysis}

Frequency distributions were used to describe cohort characteristics, including each variable included in the HAI. Univariate analysis was performed for all of the health assets against the primary outcomes. Logistic regression was performed for the HAl against the pre-specified outcomes. A multivariate regression was performed for a model with the HAl and the $\mathrm{FI}$, as well as the HAI, FI, MEWS, age and sex. After consultation with a statistician, an interaction term was then included in the model to allow them to vary.

\section{Results}

A total of 312 participants were screened, and 15 declined to participate. Of 298 participants recruited. The average age was 84.7 and 193(66\%) were women (table 2) 127(43\%) lived alone, 137(46\%) lived with others and $31(11 \%)$ lived in residential aged care. $80(27 \%)$ were admitted to an orthogeriatric unit at the time of admission, $146(49 \%)$ were admitted to a general medical unit and $70(27 \%)$ were receiving subacute care $238(80.1 \%)$, had a frailty index of greater than 0.25 with a population mean score of 0.38 
(SD 0.12) (table 2). The mean HAl score was 10.86 (SD 2.87) with a minimum of 5.5 and a maximum of 15. Table 2 describes the distribution of assets.

154 ( 56.4\%) participants had functional decline on discharge from hospital compared to baseline, and $17(5.7 \%)$ had died by 30 days. The median length of stay was 19 days IQR $(9,35)$. 33(8.1\%) were readmitted within 30 days. $213(77.7 \%)$ returned to their previous residence and 49 (17.9\%) were discharged to a new residential aged care facility. Of the 188 who returned home and were not readmitted within 30 days, 113 were able to be contacted and of those 34 (30.4\%) had a persistent functional decline.

There was a significant inverse relationship between a higher number of health assets and frailty, OR $0.36(95 \% \mathrm{Cl} 0.19-0.68)$. In analysis examining only frailty or the HAl there was no significant association with length of stay, functional decline or readmission (Table 3). After further consultation with a statistician, a logistic regression model was used that accounted for interaction. This showed a significant interaction between frailty and health assets for mortality, $\mathrm{p}=0.011(95 \% \mathrm{Cl} 1.10-2.20)$. A marginal plot demonstrates that at the lowest levels of frailty, a higher number of health assets was protective against mortality, and at the highest levels of frailty, a higher number of health assets was associated with an increased risk of mortality (see figure 1).

\section{Discussion}

This is the first study to examine the use of a health assets index in a hospital population. Hospitalisation is a critical juncture for older adults and as frailty does not explain all variation in outcomes, improving prognostication could have great benefits to individuals and hospital systems. This study demonstrates a significant interaction between health assets and frailty and provides insights into both the development and management of frailty. Among these older inpatients, a higher score on the HAI was associated with an improved baseline health status, as evidenced by the lower likelihood of frailty. The HAI alone was not predictive of mortality or functional decline, but in a model that accounted for the interaction with frailty it had differing effects for more robust compared to more frail older adults. This suggest that health assets are likely to moderate the development of frailty and to mitigate adverse outcomes for more robust older adults.

In studies of older adults, frailty alone is a better predictor of mortality than age alone. ${ }^{13}$ As not all older adults become frail at the same rate, with population ageing, it is important to develop a better understanding of factors that influence the development of frailty. ${ }^{14}$ The inverse proportional relationship between a higher number of health assets and frailty is in keeping with other studies indicating that psychosocial factors through life affect health status in older age. ${ }^{15}$ This highlights the importance of taking a life course approach to understanding ageing.

One of the strengths of the frailty index is that it utilizes a multidimensional approach to frailty, which incorporates physical, cognitive and functional components, which are all components of a 
comprehensive geriatric assessment. ${ }^{16}$

The concept of health assets was first developed and explored in the community setting in longitudinal studies. 5,7 The lack of impact of protective factors for those who were already frail is consistent with findings in the community and supports that once an individual is frail, protective factors do not improve survival. ${ }^{8}$ The Canadian Study of Health and Aging has also demonstrated that for adults aged 65 and older who were fit, a higher level of self-rated health, which is a Health Asset, protected against mortality. ${ }^{17}$ The different effect of Health Assets for those who are robust and frail is likely related to the underlying physiological differences between these groups. It may be that when someone is extremely frail, the allostatic load leads to a critical loss of physiological reserve, so that any biological impact of protective factors is negated. ${ }^{17}$

It is not clear why the higher number of health assets would be associated with a higher mortality for people who are very frail. Those with a higher number of health assets may be better supported in the community, and only present to hospital with a more significant illness. Conversely it is also possible that this frail group are particularly dependent on their assets, such as carers and emotional support, and are at greater risk when they cannot access these.

The lack of a clear proportional relationship between health assets and mortality contrasts with other studies in the hospital setting. ${ }^{9}$ Although many studies have identified an association between individual assets and improved outcomes, most of these studies did not include a measure of frailty. Multiple studies investigated mortality and functional decline up to a year after discharge from hospital, and so it may be that health assets have more impact over the months following discharge. ${ }^{18}$

This differing effect of health assets on older adults depending on frailty status indicates a challenge with measuring health assets. Although individual assets may have varying effects for individuals, the advantage of measuring multiple assets is that it the higher overall score is associated is associated with a lower level of frailty, somewhat mitigating individual variation.

Although frailty is mostly defined in physiological terms as a loss of homeostatic reserve, and is characterized by a stochastic accumulation of subcellular deficits, the impact of psychosocial factors on biology needs to be considered as part of the pathogenesis. In longitudinal community studies, a higher number of social supports are protective for older adults, when accounting for frailty and co-morbidity. 6,19 Mechanistically there is evidence that negative psychosocial factors are associated with higher levels of inflammation, which is a proposed mechanism of accelerated biological ageing and the development of frailty. ${ }^{20,21}$ It may be that a higher number of Health Assets can buffer these changes, which is why it is associated with a better health status.

In this cohort, frailty was not predictive of mortality, functional decline or length of stay, which contrasts with previous studies in the hospital setting. ${ }^{1,22}$ A recent review identified that $25 \%$ of studies in the hospital setting, increasing frailty is not predictive of mortality. ${ }^{23}$ This is in contrast studies where frailty is 
measured in the community setting. ${ }^{13,24}$ This highlights the need for further implementation work in the clinical setting to better determine how this score improves risk prediction for individuals. It also highlights the importance of utilizing data that has been collected in the community setting for hospital based risk prognostication.

Sarcopenia is a loss of muscle strength and function. This is highly prevalent in populations of older adults admitted to hospital, with prevalence at around $35 \% .{ }^{25}$ Sarcopenia is strongly associated with frailty and limitation in ADLs. ${ }^{25}$ Sarcopenia was not measured in this cohort, but it is likely to provide an important contribution to limitations in ADLs identified.

This study also highlights one of the difficulties in measurement of health assets. When a biological measure, such as optimal creatinine, is identified, a laboratory cut off range is chosen by identifying a range that will cover most of the population. For items like social connection, it is not only the frequency, but also the quality of connections that impact health. It may be more appropriate to take a subjective and individualised approach to these items.

The study has certain strengths: very few patients refused participation, and due to the use of routine data, there was a high rate of follow-up for the primary outcomes. There were also important limitations: the relationship between frailty and health assets was only measured at one point in time, so causation cannot be inferred. It is possible that mortality was under-reported as hospital record data was used, along with phone calls to individuals who had returned home, although not all could be contacted. The small sample size meant that there may have been insufficient power to detect a statistically significant result. Due to limited numbers of research personnel, not all possible participants could be approached. The statistical model that utilised an interaction was not pre-specified, so this should be interpreted with caution. People who did not speak English were not included due to the lack of resources for interpreters, which limits generalizability in a multicultural setting. The follow-up was limited to a maximum of 30 days after hospital discharge, but it is possible that over a longer duration of time after discharge, health assets may have an impact on survival. The study took place in an Australian setting, so the HAI may not be valid in other countries.

Further qualitative research specific to older adults could help determine which factors this age group think are desirable and have an immediate impact on their own wellbeing.

\section{Conclusion}

The interaction between frailty and health assets highlights the complex interplay between social, psychological and biological factors on individual rates of ageing, as defined by the measurement of frailty. Although the HAl was not predictive of adverse outcomes, this study supports further research to understand the interaction with frailty. It is not yet clear whether health assets are effective due to behavioural mechanisms, or if there is also an underlying physiological effect. The interaction between 
health assets and frailty has intriguing implications for health at the broader population level to identify strategies to improve long-term outcomes and immediate quality of life.

\section{List Of Abbreviations}

\begin{tabular}{ll} 
HAI & Health Assets Index \\
\hline FI & Frailty Index \\
\hline ADL & Activities of Daily Living \\
\hline iADLs & Instrumental Activities of Daily Living \\
\hline MEWS & Modified Early Warning System
\end{tabular}

\section{Declarations}

Ethics approval and consent to participate

Ethical approval was granted from Austin Health high-risk ethics committee (HREC/16/Austin/180). Research governance was also obtained for each participating site.

Written consent was obtained from all participants or from the person responsible if they did not have capacity.

Consent for publication

N/A

Availability of data and materials

The datasets used and/or analysed during the current study are available from the corresponding author on reasonable request

Competing interests

None to declare

\section{Funding}

Dr Kate Gregorevic received funding as part of a PhD scholarship from the Australian Postgraduate association and the Northern Foundation

\section{Authors' contributions}

KJG developed the research protocol, collected data, recruited participants, undertook data analysis and prepared the manuscript 
$\mathrm{REH}$ assisted with development of the research protocol and preparation of the manuscript

NMP assisted with development of the research protocol and preparation of the manuscript

WTL recruited participants

JW recruited participants

BC provided statistical support

KWL assisted with development of the research protocol and preparation of the manuscript

All authors have read and approved the manuscript

\section{Acknowledgements}

We would like to thank all the participants for their time.

\section{References}

1. Hubbard RE, Peel NM, Samanta M, Gray LC, Mitnitski A, Rockwood K. Frailty status at admission to hospital predicts multiple adverse outcomes. Age and ageing. 2017;46(5):801-806.

2. Boyd CM, Landefeld CS, Counsell SR, et al. Recovery of activities of daily living in older adults after hospitalization for acute medical illness. Journal of the American Geriatrics Society. 2008;56(12):2171-2179.

3. Covinsky KE, Palmer RM, Fortinsky RH, et al. Loss of independence in activities of daily living in older adults hospitalized with medical illnesses: increased vulnerability with age. Journal of the American Geriatrics Society. 2003;51(4):451-458.

4. Gregorevic K, Peel NM, Lim WK, Hubbard RE. Do Health Assets have a Protective Effect for Hospitalised Frail Older Adults? QJM : monthly journal of the Association of Physicians. 2018.

5. Seligman ME, Peterson C, Barsky AJ, et al. Postitive Health and Health Assets: Re-analysis of Longditudinal Datasets (White Paper). The University of Pennsylvania. Published 2013. Accessed Febuary 272015.

6. Andrew MK, Mitnitski AB, Rockwood K. Social vulnerability, frailty and mortality in elderly people. PloS one. 2008;3(5):e2232.

7. Hornby-Turner YC, Peel NM, Hubbard RE. Health assets in older age: a systematic review. BMJ Open. 2017;7(5):e013226.

8. Wang C, Song X, Mitnitski A, et al. Effect of health protective factors on health deficit accumulation and mortality risk in older adults in the Beijing Longitudinal Study of Aging. Journal of the American Geriatrics Society. 2014;62(5):821-828.

9. Gregorevic KJ, Lim WK, Peel NM, Martin RS, Hubbard RE. Are health assets associated with improved outcomes for hospitalised older adults? A systematic review. Archives of gerontology and geriatrics. 
2016;67:14-20.

10. Gregorevic K, Hubbard RE, Peel NM, Lim WK. Validation of the health assets index in the Australian inpatient setting: a multicentre prospective cohort protocol study. BMJ Open. 2018;8(5).

11. Subbe CP, Kruger M, Rutherford P, Gemmel L. Validation of a modified Early Warning Score in medical admissions. QJM : monthly journal of the Association of Physicians. 2001;94(10):521-526.

12. Katz S, Downs TD, Cash HR, Grotz RC. Progress in development of the index of ADL. Gerontologist. 1970;10(1):20-30.

13. Clegg A, Bates $\mathrm{C}$, Young J, et al. Development and validation of an electronic frailty index using routine primary care electronic health record data. Age and ageing. 2016;45(3):353-360.

14. Clegg A, Young J, lliffe S, Rikkert MO, Rockwood K. Frailty in elderly people. Lancet (London, England). 2013;381(9868):752-762.

15. Marshall A, Nazroo J, Tampubolon G, Vanhoutte B. Cohort differences in the levels and trajectories of frailty among older people in England. Journal of Epidemiology and Community Health. 2015;69(4):316.

16. Jones CA, McQuillan GM, Kusek JW, et al. Serum creatinine levels in the US population: third National Health and Nutrition Examination Survey. American journal of kidney diseases : the official journal of the National Kidney Foundation. 1998;32(6):992-999.

17. Lucicesare A, Hubbard RE, Searle SD, Rockwood K. An index of self-rated health deficits in relation to frailty and adverse outcomes in older adults. Aging clinical and experimental research. 2010;22(3):255-260.

18. Demakakos P, Biddulph JP, Bobak M, Marmot MG. Wealth and mortality at older ages: a prospective cohort study. Journal of Epidemiology and Community Health. 2016;70(4):346.

19. Mazzella F, Cacciatore F, Galizia G, et al. Social support and long-term mortality in the elderly: Role of comorbidity. Archives of gerontology and geriatrics. 2010;51(3):323-328.

20. Fougère $B$, Boulanger $E$, Nourhashémi $F$, Guyonnet $S$, Cesari $M$. Chronic Inflammation: Accelerator of Biological Aging. The Journals of Gerontology: Series A. 2017;72(9):1218-1225.

21. Hubbard RE, O'Mahony MS, Savva GM, Calver BL, Woodhouse KW. Inflammation and frailty measures in older people. J Cell Mol Med. 2009;13(9b):3103-3109.

22. Evans S, M S, A M, Rockwood K. The risk of adverse outcomes in hospitalized older patients in relation to a frailty index based on a comprehensive geriatric assessment. Age and ageing. 2014;43(1):127-132.

23. Theou $\mathrm{O}$, Squires $\mathrm{E}$, Mallery $\mathrm{K}$, et al. What do we know about frailty in the acute care setting? A scoping review. BMC geriatrics. 2018;18(1):139.

24. Abete P, Basile C, Bulli G, et al. The Italian version of the "frailty index" based on deficits in health: a validation study. Aging clinical and experimental research. 2017;29(5):913-926.

25. Bianchi L, Abete P, Bellelli G, et al. Prevalence and Clinical Correlates of Sarcopenia, Identified According to the EWGSOP Definition and Diagnostic Algorithm, in Hospitalized Older People: The 
GLISTEN Study. J Gerontol A Biol Sci Med Sci. 2017;72(11):1575-1581.

\section{Tables}

\begin{tabular}{|l|l|}
\hline \multicolumn{2}{|l|}{ Table 1: Baseline characteristics (293) } \\
\hline Age Mean (SD) & $84.7(7.3)$ \\
\hline Gender & $193(66.0)$ \\
\hline Female (\%) & $98(44.0)$ \\
\hline Male(\%) & $80(27.0)$ \\
\hline Ward at time of recruitment (\%) & $146(49.3)$ \\
\hline Orthogeriatrics & $70(23.7)$ \\
\hline General medicine & $127(43.1)$ \\
\hline Subacute & $137(46.4)$ \\
\hline Usual residence (\%) & $31(10.5)$ \\
\hline Home alone & $0.38(0.12) ; 0.37(0.29,0.47)$ \\
\hline Home with others & $1.6(1.2) 1$ IQR(1,2) \\
\hline Residential Care & $4.9(1.6) 6$ IQR(4,6) \\
\hline FI mean(SD); median (IQR) & $5.1(2.9) 6$ IQR(2, 8) \\
\hline MEWS mean(SD); median (IQR) & \\
\hline ADLs mean(SD); median (IQR) & \\
\hline iADLs mean(SD); median (IQR) & \\
\hline
\end{tabular}
$* \mathrm{P}<0.05$
Supplementary Tables

Figures 


\begin{tabular}{|c|c|}
\hline \multicolumn{2}{|l|}{ Table 2 HAI characteristics } \\
\hline Years school mean (SD); median( IQR) & $9.7(3.6) ; 10(8,11)$ \\
\hline \multicolumn{2}{|l|}{ Living arrangements } \\
\hline alone & $122(41.5)$ \\
\hline With others & $142(48.3)$ \\
\hline Residential Aged Care Facility & $30(10.2)$ \\
\hline \multicolumn{2}{|l|}{ Carer } \\
\hline No & $94(32.0)$ \\
\hline Yes & $170(57.8)$ \\
\hline Residential Aged Care Facility & $30(10.2)$ \\
\hline \multicolumn{2}{|l|}{ Person Supportive of discharge } \\
\hline No & $71(24.8)$ \\
\hline Yes & $215(75.2)$ \\
\hline \multicolumn{2}{|l|}{ GP } \\
\hline No & $25(8.5)$ \\
\hline Yes & $268(91.5)$ \\
\hline \multicolumn{2}{|c|}{ Private health/Department of Veterans Affairs } \\
\hline No & $148(50.9)$ \\
\hline Yes & $143(49.1)$ \\
\hline \multicolumn{2}{|l|}{ Do you own your home } \\
\hline No & $80(27.4)$ \\
\hline With mortgage & $8(2.7)$ \\
\hline Yes & 204(69.9) \\
\hline \multicolumn{2}{|c|}{ Are you able to manage on the income you have? } \\
\hline Difficult & $16(5.5)$ \\
\hline Sometimes difficult & $43(14.7)$ \\
\hline Mostly OK & $233(79.8)$ \\
\hline \multicolumn{2}{|l|}{ Number of children } \\
\hline none & $34(11.6)$ \\
\hline $1-3$ & $103(35.3)$ \\
\hline 3 or more & $155(53.1)$ \\
\hline \multicolumn{2}{|l|}{ Emotional support } \\
\hline No & $56(19.6)$ \\
\hline
\end{tabular}




\begin{tabular}{|l|l|}
\hline Yes & $230(80.4)$ \\
\hline How many times do you see/speak to someone you don't live with \\
\hline Never & $11(3.8)$ \\
\hline Less than once a week & $26(9.0)$ \\
\hline Once a week or more & $253(87.2)$ \\
\hline Left the house in the three days before admission \\
\hline No & $109(37.5)$ \\
\hline Yes & $182(62.5)$ \\
\hline Do you have control over your life & \multicolumn{2}{|l|}{} \\
\hline No & $36(12.5)$ \\
\hline Sometimes & $36(12.5)$ \\
\hline Always & $216(75.0)$ \\
\hline Quality of life & $40(13.9)$ \\
\hline Poor & $53(18.4)$ \\
\hline Sometimes good & $194(67.6)$ \\
\hline Mostly good & $124(42.7)$ \\
\hline Self-rated health & $166(58.3)$ \\
\hline Poor/fair & \multicolumn{2}{|l}{} \\
\hline Good/excellent & \\
\hline
\end{tabular}

Figure 1: Effects of Health Assets and Frailty on Mortality

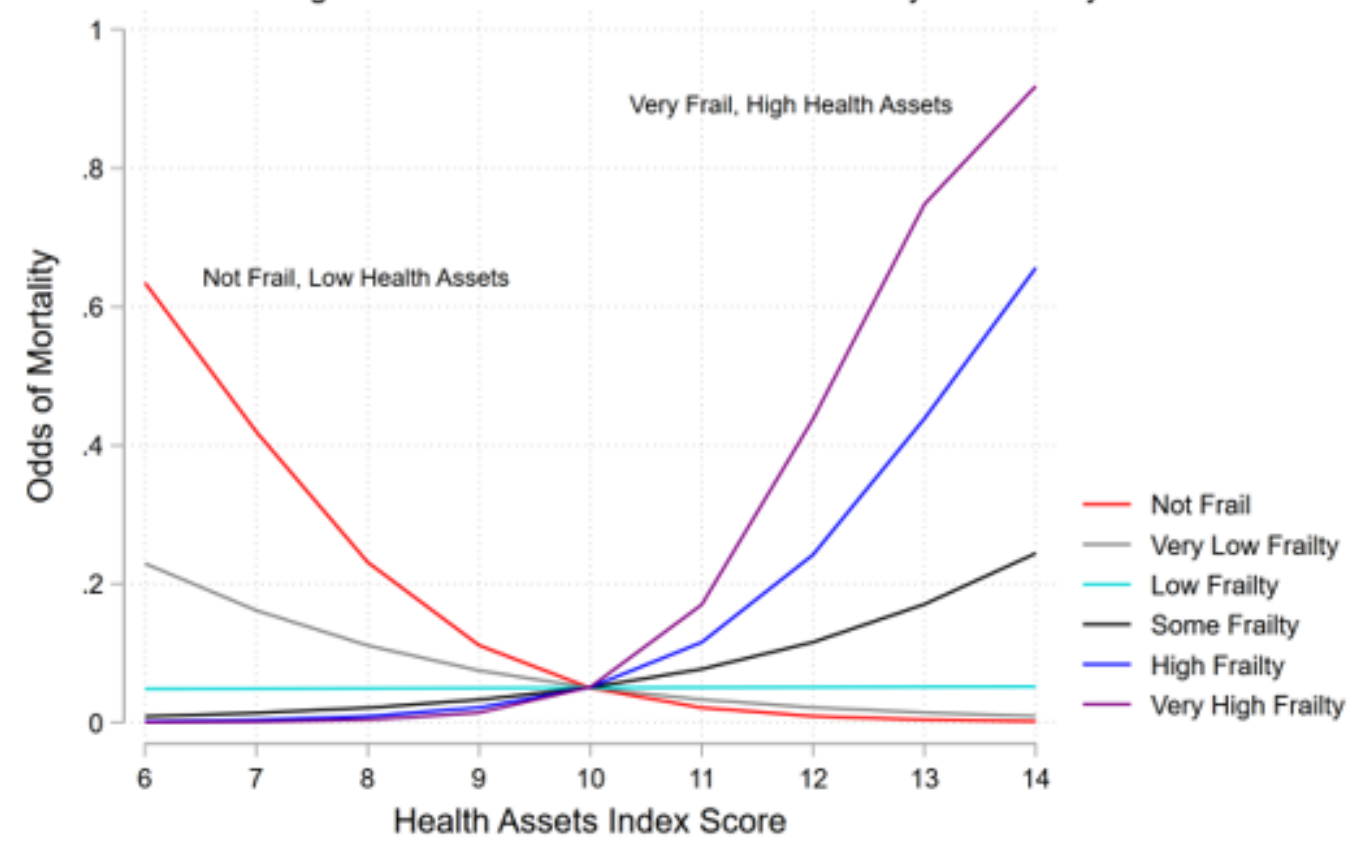




\section{Table 3: Results of Logistic regression}

\begin{tabular}{|l|l|l|l|l|l|}
\hline & $\begin{array}{l}\text { Mortality (OR, } \\
\text { 95\%CI) }\end{array}$ & $\begin{array}{l}\text { Functional } \\
\text { decline (OR } \\
\text { 95\%CI) }\end{array}$ & $\begin{array}{l}\text { Length of stay } \\
\text { (IRR,95\%CI) }\end{array}$ & $\begin{array}{l}\text { Readmission } \\
\text { within 30 } \\
\text { days (OR } \\
95 \% \text { CI })\end{array}$ & $\begin{array}{l}\text { Functional } \\
\text { decline at 30 } \\
\text { days (OR } \\
\text { 95\%CI) }\end{array}$ \\
\hline HAI & $1.01(0.77,1.33)$ & $0.93(0.82,1.06)$ & $1.02(0.97,1.08)$ & $\begin{array}{l}0.043 \\
(0.19,0.98)^{*}\end{array}$ & $\begin{array}{l}0.76(0.60, \\
0.96)^{*}\end{array}$ \\
\hline FI & $1.45(0.97,2.19)$ & $0.97(0.80,1.19)$ & $0.97(0.89,1.06)$ & $\begin{array}{l}1.40(1.03- \\
1.91)^{*}\end{array}$ & $\begin{array}{l}1.50(1.04, \\
2.26)^{*}\end{array}$ \\
\hline
\end{tabular}

\section{Model1: HAI with interaction FI}

\begin{tabular}{|l|l|l|l|l|l|}
\hline HAI & $1.10(0.83,1.45)$ & $0.92(0.81,1.06)$ & $0.99(0.90,1.09)$ & $\begin{array}{l}0.97(0.46, \\
2.06)\end{array}$ & $0.59(0.18,1.4)$ \\
\hline FI & $1.61(1.01,2.60 *$ & $0.97(0.78,1.21)$ & $1.02(0.96,1.08)$ & $\begin{array}{l}1.73(.26, \\
11.32)\end{array}$ & $0.31(0.02,6.7)$ \\
\hline
\end{tabular}

Model 2: HAI with interaction FI Age gender MEWS

\begin{tabular}{|l|l|l|l|l|l|}
\hline HAI & $1.11(0.83,1.48)$ & $0.93(0.81,1.06)$ & $1.03(0.97,1.09)$ & $\begin{array}{l}0.78 \\
(.35,1.70)\end{array}$ & $0.46(0.16,1.33)$ \\
\hline FI & $1.61(0.98,2.63)$ & $1.03(0.82,1.30)$ & $1.00(0.91,1.10)$ & $\begin{array}{l}1.10(0.15, \\
7.80)\end{array}$ & $\begin{array}{l}0.36(0.20, \\
6.43)\end{array}$ \\
\hline
\end{tabular}

\section{Figure 1}

This demonstrates a differential effect of health assets, depending on frailty status. For those who were not frail, a higher number of health assets decreased the risk of mortality. For the most frail, this relationship was reversed and a higher number of health assets was associated with increased mortality.

\section{Supplementary Files}

This is a list of supplementary files associated with this preprint. Click to download.

- supptables.docx 


\begin{tabular}{|c|c|c|}
\hline \multicolumn{3}{|c|}{ Supplementary Table 1: Frailty Index } \\
\hline & Variable name & Response/code \\
\hline 1 & Cognitive Status & normal $=0, \mathrm{CIND}=0.5$, dementia $=1$ \\
\hline 2 & Delirium & no $=0$, yes $=1$ \\
\hline 3 & Depression & no $=0$, yes $=1$ \\
\hline 4 & Anxiety & no $=0$, yes $=1$ \\
\hline 5 & Fatique & no $=0$, yes $=1$ \\
\hline 6 & $\begin{array}{l}\text { Emotional Other* (eg recent } \\
\text { bereavement) }\end{array}$ & no $=0$, yes $=1$ \\
\hline 7 & Motivation & high $=0$, low $=1$ \\
\hline 8 & Self rated health & $\begin{array}{l}\text { Excellent=0, Good=0 0.25, Fair }=0.5 \text {, } \\
\text { poor } / \text { can't say=1 }\end{array}$ \\
\hline 9 & Speech & Not impaired $=0$, impaired $=1$ \\
\hline 10 & Hearing & Not impaired $=0$, impaired $=1$ \\
\hline 11 & Vision & Not impaired $=0$, impaired $=1$ \\
\hline 12 & Strength & Not impaired $=0$, impaired $=1$ \\
\hline 13 & Sleep & normal $=0$, disrupted $=1$ \\
\hline 14 & Daytime Drowsiness & no $=0$, yes $=1$ \\
\hline 15 & Transfer & independent $=0$, assisted $=0.5$, dependent $=1$ \\
\hline 16 & Walking & independent $=0$, assisted $=0.5$, dependent $=1$ \\
\hline 17 & Aid & independent $=0$, assisted $=0.5$, dependent $=1$ \\
\hline 18 & Balance & Not impaired $=0$, impaired $=1$ \\
\hline 19 & Falls & no $=0$, yes $=1$ \\
\hline 20 & Falls Number & no falls $=0,1-3$ falls $=0.5$, more than 3 falls $=1$ \\
\hline 21 & Bowel & normal $=0$, incontinence $=1$ \\
\hline 22 & Bladder & normal $=0$, incontinence $/$ catheter $=1$ \\
\hline 23 & Weight & good $=0$, obese $/$ underweight $=1$ \\
\hline 24 & Weight change & Loss/gain $=1$ \\
\hline 25 & Appetite & normal $=0$, poor $=1$ \\
\hline 26 & Feeding & no $=0$, yes $=1$ \\
\hline 27 & Bathing & independent $=0$, assisted $=0.5$, dependent $=1$ \\
\hline 28 & Dressing & independent $=0$, assisted $=0.5$, dependent $=1$ \\
\hline 29 & Toileting & independent $=0$, assisted $=0.5$, dependent $=1$ \\
\hline 30 & Medication use & independent $=0$, assisted $=0.5$, dependent $=1$ \\
\hline $\begin{array}{l}31- \\
49\end{array}$ & Medical problems & $\begin{array}{l}\text { Count of medical problems (begins with } \\
\text { reason for referral) }\end{array}$ \\
\hline $\begin{array}{l}49- \\
50\end{array}$ & 54-55 Count of medications & If $<7=0$, from 8 to $12=0.5,13$ and more $=1$ \\
\hline
\end{tabular}




\begin{tabular}{|c|c|c|}
\hline \multicolumn{3}{|c|}{ Supplementary Table 2: Health Assets Index and Scoring System } \\
\hline $\begin{array}{l}\text { Domain } \\
\text { and } \\
\text { Question } \\
\text { number }\end{array}$ & Question & Scoring system \\
\hline \multicolumn{3}{|c|}{ Education } \\
\hline 1 & $\begin{array}{l}\text { At approximately what age did you start school? } \\
\text { At approximately what age did you finish school? }\end{array}$ & $\begin{array}{l}0 \text { if }<9.5 \text { years } \\
1 \text { if } \geq 9.5 \text { vears }\end{array}$ \\
\hline \multicolumn{3}{|l|}{ Carer } \\
\hline 2 & $\begin{array}{l}\text { Do you have a carer or someone you can rely on to } \\
\text { help with day-to-day activities? }\end{array}$ & $\begin{array}{l}0 \text { no } \\
1 \text { yes }\end{array}$ \\
\hline 3 & $\begin{array}{l}\text { Do you have a support person who is positive towards } \\
\text { discharge or maintaining residence in the } \\
\text { community? }\end{array}$ & $\begin{array}{l}0 \text { no } \\
1 \text { yes }\end{array}$ \\
\hline 4 & Do you live alone or with others? & $\begin{array}{l}0 \text { alone } \\
1 \text { with others }\end{array}$ \\
\hline \multicolumn{3}{|c|}{ General Practitioner } \\
\hline 5 & Do you have a regular General Practitioner? & $\begin{array}{l}0 \text { no } \\
1 \text { yes }\end{array}$ \\
\hline \multicolumn{3}{|l|}{ Financial } \\
\hline 6 & $\begin{array}{l}\text { Do you have private health insurance or other form of } \\
\text { health services over such as Dept of Veterans' Affairs } \\
\text { Gold Card?? }\end{array}$ & $\begin{array}{l}0 \text { no } \\
1 \text { yes }\end{array}$ \\
\hline 7 & Do you own your own home? & $\begin{array}{l}0 \text { No } \\
0.5 \text { yes with } \\
\text { mortgage } \\
1 \text { yes }\end{array}$ \\
\hline 8 & $\begin{array}{l}\text { How do you manage on the income you have } \\
\text { available? }\end{array}$ & $\begin{array}{l}0 \text { It is } \\
\text { difficult/impossible } \\
\text { most of the time } \\
0.5 \text { It is difficult } \\
\text { some of the time } \\
1 \text { It is } \\
\text { mostly/always } \\
\text { manageable }\end{array}$ \\
\hline \multicolumn{3}{|c|}{ Number of children } \\
\hline$\sigma_{10}$ & How many children do you have? & $\begin{array}{l}0 \text { zero } \\
0.5 \text { for one to two } \\
1 \text { for three or } \\
\text { more }\end{array}$ \\
\hline \multicolumn{3}{|c|}{ Social engagement } \\
\hline 10 & $\begin{array}{l}\text { Can you count on anyone to provide you with } \\
\text { emotional support eg talking over a problem, or } \\
\text { helping with a decision? }\end{array}$ & $\begin{array}{l}0 \text { no } \\
1 \text { yes }\end{array}$ \\
\hline 11 & $\begin{array}{l}\text { How many times a week do you see or talk to a family } \\
\text { member or friend who does not live with you? }\end{array}$ & $\begin{array}{l}0 \text { never } \\
0.5 \text { less that once } \\
\text { a week } \\
1 \text { once a week or } \\
\text { more }\end{array}$ \\
\hline 12 & $\begin{array}{l}\text { In the } 3 \text { days prior to the onset of the illness } \\
\text { precipitating admission, number of days went out of } \\
\text { the house or building in which he/she resides }\end{array}$ & $\begin{array}{l}0 . \text { No days out } \\
1 \text { days out }\end{array}$ \\
\hline \multicolumn{3}{|c|}{ Psychosocial wellbeing } \\
\hline 13 & Do you have control over the important things in life? & $\begin{array}{l}0 \text { never } \\
0.5 \text { sometimes } \\
1 \text { mostly }\end{array}$ \\
\hline 14 & Overall how would you rate your quality of life? & 0 mostly bad \\
\hline
\end{tabular}




\begin{tabular}{|l|l|l|} 
& & $\begin{array}{l}0.5 \text { sometimes } \\
\text { good, sometimes } \\
\text { bad } \\
1 \text { mostly good }\end{array}$ \\
\hline 15 & In general would you say your health is: & $\begin{array}{l}0 \text { poor/fair } \\
1 \text { good excellent }\end{array}$ \\
\hline
\end{tabular}

\begin{tabular}{|l|l|}
\hline \multicolumn{2}{|l|}{ Supplementary Table 3: Outcomes } \\
\hline 30 day mortality & $281(94.3)$ \\
\hline No & $17(5.7)$ \\
\hline Yes & $3.6(2.0)$ \\
\hline ADL at discharge mean (SD) N=277 & \\
\hline Functional Decline(\%) & $119(43.6)$ \\
\hline No & $154(56.4)$ \\
\hline Yes & $25.3(23.8) ; 19(9,35)$ \\
\hline Length of stay mean (SD); median (IQR) & $5.1(1.3)$ IQR $(4,6)$ \\
\hline ADL 30 days after discharge N=112 & $4.8(2.5)$ IQR(3,7) \\
\hline iADL 30 days after discharge N=110 & \\
\hline Readmission 30 days & $235(91.9)$ \\
\hline Yes & $33(8.1)$ \\
\hline No & $32(71.2)$ \\
\hline Functional decline at 30 days(\%) in those who returned home \\
\hline No & $79(28.8)$ \\
\hline Yes &
\end{tabular}

